\title{
Undernutrition in early life and body composition of adolescent males from a birth cohort study
}

\author{
Denise P. Gigante ${ }^{1,2}$, Cesar G. Victora ${ }^{1}$, Bernardo L. Horta ${ }^{1}$ and Rosângela C. Lima ${ }^{1,3}$ \\ ${ }^{1}$ Post-Graduate Program in Epidemiology and \\ ${ }^{2}$ Nutrition Department, Universidade Federal de Pelotas, Pelotas, RS, Brazil \\ ${ }^{3}$ Universidade Católica de Pelotas, Pelotas, RS, Brazil
}

(Received 5 April 2006 - Revised 16 October 2006 - Accepted 30 October 2006)

\begin{abstract}
The evidence for an association between poor nutrition in early life and subsequent obesity is inconclusive. In the present study, we investigated the associations between stunting, wasting and underweight at 2 and 4 years of age, and body composition in adolescence in male subjects studied since birth. The 1982 Pelotas Birth Cohort Study included all children born in maternity hospitals and living in the urban area of the city of Pelotas, Southern Brazil. All males born in 1982 were legally required to enlist in the army between January and April 2000. We were thus able to track 2250 subjects in 2000 (78.9\% of the original cohort). Anthropometric measurements were collected in 1984 and 1986, and body composition was assessed in 2000. In the present analysis, we used as predictors the nutritional indices height-for-age, weight-for-height and weight-for-age presented in six categories. Outcomes included fat, lean and body mass indices and fat:lean mass ratio, derived from anthropometric and bioimpedance measurements. ANOVA and linear regression were used in the analyses to adjust for confounding. All predictors were positively associated with fat and body mass indices. Height-for-age $Z$ score at age 2 or 4 years was not associated with lean mass index, but all other predictors were associated. Fat:lean mass ratio was associated only with weight-for-height $Z$ score. Our results suggest that undernutrition is not a risk factor for overweight and obesity in our population and may partially protect against fatness in adolescence.
\end{abstract}

Nutritional indices: Body composition: Adolescent male: Cohort study

In face of the epidemic of overweight and obesity affecting middle- and high-income countries, growing attention is being paid to the role of early determinants of adult size (Prentice \& Moore, 2005). Of particular interest is the possibility that individuals who have suffered from undernutrition in early life, but who have later been exposed to Westerntype diets and lifestyle - a common situation in transitional societies - are at greater risk of overweight and chronic disease (Prentice, 2006).

The association between stunting and overweight in children was shown in a cross-sectional study conducted in four countries in nutritional transition (Russia, Brazil, South African, China). The risk of being overweight for a stunted child ranged from 1.7 to 7.8 (Popkin et al. 1996). In a review of early nutrition and later-life adiposity, Martorell and colleagues concluded that high birth weight was associated with subsequent obesity, whereas the evidence for poor nutrition in early life as a risk factor for increased fatness later in life was inconclusive (Martorell et al. 2001). In a more recent review, the increase in weight or BMI and rapid growth during infancy were associated with obesity in childhood and adulthood (Baird et al. 2005).

The association between nutritional indices in childhood and later body composition has been studied (Walker et al.
2002), stunted children having significantly less total and lean tissue than non-stunted children, although there was no difference in the percentages of fat mass and lean mass (Cameron et al. 2005). In Brazil, stunted boys accumulated more body fat and gained less lean mass than non-stunted boys, and stunted girls showed a significantly higher percentage of fat mass at the end of follow-up, whereas non-stunted girls showed no significant differences in the percentage of fat mass over time (Martins et al. 2004).

A cohort of boys has been studied since their birth (1982) in Pelotas, a city in Southern Brazil. Subjects were subsequently traced in 1984, 1986 and 2000, and nutritional status and body composition were assessed. The aim of the present analysis was to study the associations between stunting, wasting and underweight at 2 and 4 years of age, and the body composition of male adolescents. The 1982 Pelotas Birth Cohort allows for an examination of such associations using body composition indices that have not been considered in other studies.

\section{Methods \\ All births taking place in the maternity hospitals in the city of Pelotas in 1982 were included in the Pelotas Birth Cohort Study. The methodological details of this study have been}

Abbreviations: FM:LM, fat mass:lean mass; TBW, total body water.

* Corresponding author: Dr Denise Petrucci Gigante, fax +55 53 32712645, email denise @epidemio-ufpel.org.br 
published elsewhere (Barros et al. 1990; Victora et al. 2003; Victora \& Barros, 2006).

The perinatal study took place at the hospitals and included 5914 births. Our research team measured and interviewed mothers and weighed both mothers and babies. The first follow-up visit attempted to locate the 1916 children born in the first 4 months of 1982 using the home address obtained during the maternity interview. A total of $79.3 \%$ of all children were traced, and their mothers were interviewed. The second and third follow-ups were conducted based on a census of all households in the urban area of Pelotas, in order to avoid losses. This approach resulted in follow-up rates of $87.2 \%$ and $84.1 \%$, respectively.

Children were weighed using portable mechanical scales (CMS Weighing Equipment Ltd, London, UK), and supine length (1984) and height (1986) were measured using boards manufactured locally according to international specifications (AHRTAG; Healthlink Worldwide, London, UK). The precision for weight and length:height was $100 \mathrm{~g}$ and $0.1 \mathrm{~cm}$, respectively. Nutritional indices were expressed as the $Z$ score of the National Center for Health Statistics (1977).

From January to April 2000, all males born in 1982 were legally required to enlist in the army. Of the 3037 boys in the cohort, 2047 were identified when enlisting and were linked to their birth records. Other subjects were located at their last known address, leading to a total 2250 subjects who were interviewed and subjected to physical examination, including measurements of blood pressure, height, sitting height, weight and body composition collected by the study team. Taking into account the 147 cohort members who were known to have died, we were able to track $78.9 \%$ of the 3037 males originally included in the cohort. Ethical approval for the study was obtained from Medical Ethics Committee of the Federal University of Pelotas. The confidentiality of all the information was ensured, and verbal and written consents were obtained in 1982 and 2000, respectively.

In the present analysis, the predictors investigated were height-for-age $Z$ score, weight-for-height $Z$ score and weight-for-age $Z$ score, at age 2 and 4 years. These variables were categorised by $Z$ scores of less than $-2,-2$ to $-1 \cdot 1$, -1 to $0,0 \cdot 1$ to $1,1 \cdot 1$ to 2 and more than 2 in the analyses. Confounding variables included family income in 1982 (the sum of the monthly incomes of all working persons living in the household, expressed as multiples of the minimum wage), pre-gestational weight (from the antenatal care register or by asking the mother about her weight before pregnancy), maternal height (measured by the research team soon after admission to the maternity hospital), weight gain during pregnancy (calculated as the difference between the weight obtained immediately after birth and the pre-gestational weight) and the child's age and birth weight (measured in grams after birth by trained interviewers, using regularly calibrated paediatric scales).

Outcomes variables were fat mass index, lean mass index, $\mathrm{BMI}$ and fat mass:lean mass ratio $\left(\mathrm{FM}: \mathrm{LM}^{2 \cdot 3}\right)$. Fat mass index, lean mass index and BMI were calculated by dividing fat, lean and body mass, respectively, by the square of height. When enlisting in the army, participants were weighed in their underpants using a Tanita Body Fat Analyzer Scale (Model TBF 305; Tanita, Tokyo, Japan). Fat and lean mass were estimated in kilograms using the information obtained from the Tanita scale. These measures were corrected by means of a validation substudy, conducted in a mirror sample of forty-eight participants in the age range of the study cohort, in which total body water (TBW) was assessed by ${ }^{2} \mathrm{H}$ dilution (Wells et al. 2003). This study showed that although Tanita predicted TBW and percentage of fat without significant bias in young male Brazilian adults as a whole, this technique overestimated TBW and underestimated fatness in subjects with lower TBW values. New algorithms were derived, predicting TBW from various combinations of data on weight, height and impedance results, and the present results incorporate this correction. Fat mass was calculated by dividing corrected TBW by 0.732 , and lean mass - used as synonymous with fat-free mass - was defined as the difference between weight and fat mass.

We used ANOVA and the $F$ test to examine the association between predictors and confounding variables, and outcomes. The selection of confounding factors was based on the assumption that socioeconomic conditions might influence body size and composition in children and adults. Indicators of maternal body size (pre-pregnancy weight, height and weight gain during pregnancy) were included in an attempt to adjust for genetic growth potential. Information on paternal size was not available. Because birth weight may influence size throughout life, it was also adjusted for in the analyses. Data on birth length were not collected.

Associations between the above variables and both exposures (anthropometry at ages 2 and 4 years) and outcomes (body composition at 18 years) were tested; variables showing associations at the $P<0.2$ level with at least one exposure and one outcome variable were considered as potential confounders (Maldonado \& Greenland, 1993) and included in the adjusted analyses. Linear regression analyses were carried out for body, fat and lean mass indices and for FM:LM ${ }^{2 \cdot 3}$. Potential confounding factors were investigated, and those showing association with the outcome and predictors $(P<0 \cdot 2)$ were subjected to the multivariate analyses. Confounding factors were included as continuous variables in the linear regression models. The regression model included all potential confounding factors, and results are shown for the predictors.

\section{Results}

A comparison of the socioeconomic characteristics of boys examined in 2000 and those of the original cohort showed that the lowest income group - which included subjects with low birth weight, stunting at age 2 and 4 years, and underweight at age 2 years - were less likely to have been examined in the 2000 follow-up. The differences were, however, small: three percentage points or less. These differences were due to the fact that adolescents who were lost or deceased belonged to the lower income group - three times the minimum wages or less - and were low birth weight, stunting, wasting and underweight at age 2 and 4 years (Table 1).

Means and standard deviations for fat mass index, lean mass index, BMI and FM:LM ${ }^{2 \cdot 3}$ were 3.7 (SD 1.5), 18.6 (SD 2.3) and $22.3(\mathrm{SD} 3.7) \mathrm{kg} / \mathrm{m}^{2}$ and $1.0 \times 10^{-3}$ (SD $0.2 \times 10^{-3}$ ), respectively. These outcomes were correlated with a number of potential confounding factors, and the following significant associations were detected: family income and maternal 
Table 1. Characteristics of the original 1982 Pelotas birth cohort and adolescents included in the analyses (Pelotas, 1982-2001)

\begin{tabular}{|c|c|c|c|c|}
\hline Variable & Original cohort ( $n$ 3037) (\%) & Included in analysis ( $n$ 2250) (\%) & Losses ( $n$ 640) (\%) & Deaths $(n 147)(\%)$ \\
\hline \multicolumn{5}{|c|}{ Family income (minimum wage) } \\
\hline$\leq 1$ & 21.9 & 18.7 & 28.6 & 44.1 \\
\hline $1 \cdot 1-3$ & $48 \cdot 2$ & $49 \cdot 1$ & $45 \cdot 7$ & $46 \cdot 2$ \\
\hline $3 \cdot 1-6$ & $17 \cdot 9$ & $19 \cdot 9$ & 13.7 & $6 \cdot 2$ \\
\hline $6 \cdot 1-10$ & $6 \cdot 1$ & 6.4 & $6 \cdot 0$ & $2 \cdot 1$ \\
\hline$>10$ & 5.5 & $5 \cdot 6$ & $6 \cdot 1$ & 1.4 \\
\hline \multicolumn{5}{|l|}{ Birth weight } \\
\hline$<2500 \mathrm{~g}$ & 8.0 & 5.9 & 8.6 & $39 \cdot 0$ \\
\hline $2500-2999 \mathrm{~g}$ & $20 \cdot 6$ & 20.1 & 21.4 & $24 \cdot 0$ \\
\hline $3000-3499 \mathrm{~g}$ & $37 \cdot 3$ & 38.1 & $37 \cdot 7$ & $22 \cdot 6$ \\
\hline $3500-3999 \mathrm{~g}$ & $26 \cdot 6$ & 27.9 & $25 \cdot 0$ & $13 \cdot 0$ \\
\hline$\geq 4000 \mathrm{~g}$ & 7.5 & $8 \cdot 0$ & $7 \cdot 2$ & 1.4 \\
\hline \multicolumn{5}{|l|}{ Stunting in $1984^{*}$} \\
\hline No & 86.9 & 88.8 & $78 \cdot 6$ & \\
\hline Yes & 13.1 & $11 \cdot 2$ & 21.4 & \\
\hline \multicolumn{5}{|l|}{ Wasting in $1984^{*}$} \\
\hline No & 87.8 & 88.8 & 84.6 & \\
\hline Yes & $12 \cdot 2$ & $11 \cdot 2$ & $15 \cdot 4$ & \\
\hline \multicolumn{5}{|c|}{ Underweight in $1984^{\star}$} \\
\hline No & 93.8 & 95.1 & 88.5 & \\
\hline Yes & $6 \cdot 2$ & 4.9 & 11.5 & \\
\hline \multicolumn{5}{|l|}{ Stunting in $1986^{*}$} \\
\hline No & 91.4 & 92.9 & $85 \cdot 2$ & \\
\hline Yes & $8 \cdot 6$ & $7 \cdot 1$ & $14 \cdot 8$ & \\
\hline \multicolumn{5}{|l|}{ Wasting in $1986^{*}$} \\
\hline No & $92 \cdot 3$ & 93.1 & 88.4 & \\
\hline Yes & $7 \cdot 7$ & 6.9 & 11.6 & \\
\hline \multicolumn{5}{|c|}{ Underweight in $1986^{*}$} \\
\hline No & $96 \cdot 9$ & 97.5 & 93.9 & \\
\hline Yes & $3 \cdot 1$ & 2.5 & $6 \cdot 1$ & \\
\hline Total & $100 \%$ & $100 \%$ & $100 \%$ & $100 \%$ \\
\hline
\end{tabular}

${ }^{*}$ Most of the deaths occurred during first year of life.

weight gain during pregnancy were positively associated with three indices, whereas there was no association with FM:LM ${ }^{2.3}$; positive associations were observed between maternal height and fat mass index and $\mathrm{FM}: \mathrm{LM}^{2 \cdot 3}$; and maternal pre-gestational weight was positively associated with all outcomes. These variables were included as potential confounding factors in the analyses of the association of undernutrition. Current family income was also associated with fat, lean and body mass indices. There was no difference in the results when analyses were repeated with current instead of baseline family income.

Early-life anthropometric variables tended to be positively associated with the three indices measured at 18 years, and FM:LM ${ }^{2 \cdot 3}$ was not associated with any indices at either age (Table 2).

Most associations remained positive in the adjusted analysis. However, the crude association between height-for-age at 2 years and lean mass index disappeared (Table 2 ). Associations with the FM:LM ${ }^{2 \cdot 3}$ ratio remained NS after adjustment; the only exception was weight-for-height at age 4 years, which showed a fairly positive association.

The association between underweight and wasting, and body composition at age 18 years seems to be stronger when these exposures were measured at age 4 years than when they were measured at age 2 years, but there was no clear age effect for stunting.

All analyses were repeated including birth weight as a confounding factor, with similar results (data not shown). Birth weight was positively associated with fat, lean and body mass indices, and inversely associated with FM:LM ${ }^{2 \cdot 3}$.

\section{Discussion}

Our cohort has the advantage of being population-based and of including several measurements at different ages. The overall rate of follow-up was reasonably high (78.9\%), the sample size was large, and body composition was assessed. Recently proposed indices of body composition (Wells \& Victora, 2005) were used to separate fatness from sheer body size. The validation study using ${ }^{2} \mathrm{H}$ dilution to correct TBW is another advantage of our study. Body composition indices were corrected through algorithms predicting TBW from combinations of data on weight, height and impedance.

On the negative side, adolescents who were effectively examined tended to be somewhat wealthier and less likely to have been malnourished in childhood. Part of this difference is due to survival bias: about $5 \%$ of the cohort is known to have died before this date, and deaths were more common among the poor, those with a low birth weight and malnourished children (Victora \& Barros, 2006). Other limitations were that the study was restricted to males because of the army recruitment scheme, and that the outcome was measured in late adolescence rather than among adults. Although height velocity rises sharply to a peak before age 18 years, young adults may still grow $2-3 \mathrm{~cm}$ between the ages of 19 and 20 (Tanner, 1990). 
Table 2. Adjusted mean and $95 \% \mathrm{Cl}$ of fat, lean and body mass indices and fat:lean mass ratio in 2000 according to predicting factors (Pelotas, 1982-2000)

\begin{tabular}{|c|c|c|c|c|c|c|c|c|c|c|c|c|c|}
\hline \multirow[b]{2}{*}{ Variable } & \multirow[b]{2}{*}{$n$} & \multicolumn{3}{|c|}{ Fat mass index ${ }^{*}$} & \multicolumn{3}{|c|}{ Lean mass indext } & \multicolumn{3}{|c|}{ Body mass index ${ }^{*}$} & \multicolumn{3}{|c|}{ Fat/lean mass ratio $\ddagger \S$} \\
\hline & & Mean & $95 \% \mathrm{Cl}$ & $P$ value & Mean & $95 \% \mathrm{Cl}$ & $P$ value & Mean & $95 \% \mathrm{Cl}$ & $P$ value & Mean & $95 \% \mathrm{Cl}$ & $P$ value \\
\hline Length for age $Z$ score at age 2 years & & & & & & & & & & & & & 0.9 \\
\hline$<-2$ & 224 & & & $<0.001$ & & & 0.15 & & & 0.008 & & & \\
\hline-2 to $-1 \cdot 1$ & 520 & $3 \cdot 3$ & $3 \cdot 0,3 \cdot 5$ & & $18 \cdot 4$ & $18 \cdot 0,18 \cdot 7$ & & $21 \cdot 6$ & $21 \cdot 1,22 \cdot 1$ & & 1.05 & $1.03,1.09$ & \\
\hline-1 to 0 & 734 & 3.5 & $3 \cdot 3,3 \cdot 6$ & & $18 \cdot 4$ & $18 \cdot 2,18 \cdot 7$ & & 21.9 & $21 \cdot 6,22 \cdot 2$ & & 1.05 & $1.03,1.07$ & \\
\hline $0 \cdot 1$ to 1 & 404 & 3.7 & $3.6,3.9$ & & $18 \cdot 6$ & $18 \cdot 4,18 \cdot 7$ & & $22 \cdot 3$ & $22 \cdot 0,22 \cdot 6$ & & 1.05 & $1.03,1.07$ & \\
\hline $1 \cdot 1$ to 2 & 125 & 4.0 & $3 \cdot 8,4 \cdot 1$ & & $18 \cdot 7$ & $18 \cdot 5,19 \cdot 0$ & & $22 \cdot 7$ & $22 \cdot 3,23 \cdot 0$ & & 1.02 & $1.00,1.05$ & \\
\hline$>2$ & 12 & 4.4 & $4 \cdot 1,4 \cdot 7$ & & $19 \cdot 1$ & $18 \cdot 7,19.5$ & & $23 \cdot 5$ & $22 \cdot 9,24 \cdot 2$ & & 1.03 & $0.99,1.07$ & \\
\hline & & $5 \cdot 1$ & $4 \cdot 3,5 \cdot 9$ & & $20 \cdot 2$ & $18 \cdot 9,21 \cdot 5$ & & $25 \cdot 4$ & $23 \cdot 3,27 \cdot 4$ & & 1.03 & $0.91,1.15$ & \\
\hline Weight for length $Z$ score at age 2 years & & & & $<0.001$ & & & $<0.001$ & & & $<0.001$ & & & 0.47 \\
\hline$<-2$ & 20 & $2 \cdot 9$ & $2 \cdot 1,3 \cdot 6$ & & $16 \cdot 6$ & $15 \cdot 5,17 \cdot 7$ & & $19 \cdot 5$ & $17 \cdot 7,21 \cdot 2$ & & $1 \cdot 11$ & $1 \cdot 00,1 \cdot 22$ & \\
\hline-2 to $-1 \cdot 1$ & 198 & 3.0 & $2 \cdot 8,3 \cdot 3$ & & $17 \cdot 3$ & $17 \cdot 0,17 \cdot 7$ & & $20 \cdot 3$ & $19 \cdot 8,20 \cdot 9$ & & 1.04 & $1.00,1.07$ & \\
\hline-1 to 0 & 646 & 3.5 & $3.3,3.6$ & & $18 \cdot 1$ & $18 \cdot 0,18 \cdot 3$ & & 21.5 & $21 \cdot 3,21 \cdot 8$ & & 1.05 & $1.03,1.06$ & \\
\hline $0 \cdot 1$ to 1 & 726 & 3.8 & $3.7,3.9$ & & $18 \cdot 8$ & $18.6,18.9$ & & 22.5 & $22 \cdot 3,22 \cdot 8$ & & 1.04 & $1.02,1.05$ & \\
\hline 1.1 to 2 & 331 & $4 \cdot 2$ & $4 \cdot 1,4 \cdot 4$ & & $19 \cdot 5$ & $19 \cdot 2,19 \cdot 7$ & & $23 \cdot 7$ & $23 \cdot 3,24 \cdot 1$ & & 1.04 & $1.02,1.05$ & \\
\hline$>2$ & 98 & 4.8 & $4 \cdot 5,5 \cdot 1$ & & $20 \cdot 3$ & $19 \cdot 8,20 \cdot 7$ & & $25 \cdot 1$ & $24 \cdot 4,25 \cdot 9$ & & 1.04 & $1.00,1.09$ & \\
\hline Weight for age $Z$ score at age 2 years & & & & $<0.001$ & & & $<0.001$ & & & $<0.001$ & & & 0.58 \\
\hline$<-2$ & 97 & $2 \cdot 7$ & $2 \cdot 4,3 \cdot 0$ & & $17 \cdot 2$ & $16 \cdot 7,17 \cdot 7$ & & $19 \cdot 9$ & $19 \cdot 1,20 \cdot 7$ & & 1.01 & $0.96,1.06$ & \\
\hline-2 to $-1 \cdot 1$ & 398 & $3 \cdot 3$ & $3.2,3.5$ & & $18 \cdot 0$ & $17 \cdot 8,18 \cdot 3$ & & 21.4 & $21 \cdot 0,21 \cdot 7$ & & 1.05 & $1.03,1.08$ & \\
\hline-1 to 0 & 724 & 3.5 & $3.4,3.6$ & & $18 \cdot 3$ & $18 \cdot 2,18 \cdot 5$ & & 21.9 & $21 \cdot 6,22 \cdot 1$ & & 1.04 & $1.02,1.06$ & \\
\hline $0 \cdot 1$ to 1 & 512 & 4.0 & $3 \cdot 9,4 \cdot 2$ & & $18 \cdot 9$ & $18 \cdot 7,19 \cdot 1$ & & $22 \cdot 9$ & $22 \cdot 6,23 \cdot 3$ & & 1.05 & $1.03,1.07$ & \\
\hline 1.1 to 2 & 216 & $4 \cdot 3$ & $4 \cdot 1,4 \cdot 5$ & & 19.5 & $19 \cdot 1,19 \cdot 8$ & & $23 \cdot 7$ & $23 \cdot 2,24 \cdot 2$ & & 1.02 & $0.99,1.05$ & \\
\hline$>2$ & 72 & $5 \cdot 1$ & $4.8,5.5$ & & 20.5 & $19 \cdot 9,21 \cdot 0$ & & $25 \cdot 6$ & $24 \cdot 8,26 \cdot 5$ & & 1.03 & $0.97,1.08$ & \\
\hline Height for age $Z$ score at age 4 years & & & & $<0.001$ & & & 0.01 & & & $<0.001$ & & & 0.69 \\
\hline$<-2$ & 138 & $3 \cdot 1$ & $2 \cdot 8,3 \cdot 4$ & & $18 \cdot 2$ & $17 \cdot 7,18 \cdot 6$ & & 21.4 & $20 \cdot 6,22 \cdot 1$ & & 1.05 & $1.01,1.09$ & \\
\hline-2 to $-1 \cdot 1$ & 401 & 3.4 & $3.2,3.5$ & & $18 \cdot 3$ & $18 \cdot 0,18 \cdot 5$ & & 21.6 & $21 \cdot 2,22 \cdot 0$ & & 1.06 & $1.04,1.08$ & \\
\hline-1 to 0 & 750 & 3.7 & $3 \cdot 6,3 \cdot 8$ & & $18 \cdot 6$ & $18 \cdot 4,18 \cdot 8$ & & $22 \cdot 2$ & $21 \cdot 9,22 \cdot 5$ & & 1.04 & $1.03,1.06$ & \\
\hline $0 \cdot 1$ to 1 & 510 & 4.0 & $3 \cdot 9,4 \cdot 1$ & & $18 \cdot 7$ & $18.5,18.9$ & & $22 \cdot 7$ & $22 \cdot 3,23 \cdot 0$ & & 1.04 & $1.02,1.06$ & \\
\hline $1 \cdot 1$ to 2 & 164 & 4.4 & $4 \cdot 2,4 \cdot 7$ & & $19 \cdot 2$ & $18 \cdot 8,19 \cdot 6$ & & $23 \cdot 6$ & $23 \cdot 0,24 \cdot 2$ & & 1.01 & $0.98,1.05$ & \\
\hline$>2$ & 20 & $5 \cdot 0$ & $4 \cdot 4,5 \cdot 7$ & & $20 \cdot 2$ & $19 \cdot 2,21 \cdot 2$ & & $25 \cdot 3$ & $23 \cdot 7,26 \cdot 9$ & & 0.96 & $0.86,1.06$ & \\
\hline Weight for height $Z$ score at age 4 years & & & & $<0.001$ & & & $<0.001$ & & & $<0.001$ & & & 0.05 \\
\hline$<-2$ & 3 & 1.8 & $0 \cdot 2,3 \cdot 3$ & & $15 \cdot 4$ & $13 \cdot 1,17 \cdot 8$ & & $17 \cdot 2$ & $13 \cdot 7,20 \cdot 7$ & & 0.86 & $0 \cdot 62,1 \cdot 10$ & \\
\hline-2 to $-1 \cdot 1$ & 129 & $2 \cdot 9$ & $2 \cdot 6,3 \cdot 2$ & & $17 \cdot 0$ & $16 \cdot 6,17 \cdot 4$ & & $19 \cdot 8$ & $19 \cdot 2,20 \cdot 4$ & & 1.03 & $0.99,1.07$ & \\
\hline-1 to 0 & 593 & $3 \cdot 3$ & $3 \cdot 1,3 \cdot 4$ & & $17 \cdot 8$ & $17 \cdot 6,18 \cdot 0$ & & $21 \cdot 0$ & $20 \cdot 8,21 \cdot 3$ & & 1.03 & $1.01,1.05$ & \\
\hline 0.1 to 1 & 866 & 3.7 & $3.6,3 \cdot 8$ & & $18 \cdot 6$ & $18 \cdot 5,18 \cdot 8$ & & $22 \cdot 3$ & $22 \cdot 1,22 \cdot 6$ & & 1.04 & $1.03,1.06$ & \\
\hline $1 \cdot 1$ to 2 & 289 & 4.6 & $4 \cdot 4,4 \cdot 8$ & & $20 \cdot 1$ & $19 \cdot 8,20 \cdot 3$ & & $24 \cdot 7$ & $24 \cdot 3,25 \cdot 1$ & & 1.06 & $1.03,1.09$ & \\
\hline$>2$ & 100 & $5 \cdot 6$ & $5 \cdot 3,5 \cdot 9$ & & $21 \cdot 3$ & $20 \cdot 9,21 \cdot 8$ & & $26 \cdot 9$ & $26 \cdot 2,27 \cdot 7$ & & 1.09 & $1 \cdot 05,1 \cdot 14$ & \\
\hline Weight for age $Z$ score at age 4 years & & & & $<0.001$ & & & $<0.001$ & & & $<0.001$ & & & 0.55 \\
\hline$<-2$ & 47 & $2 \cdot 5$ & $2 \cdot 0,3 \cdot 0$ & & $16 \cdot 6$ & $15 \cdot 8,17 \cdot 3$ & & $18 \cdot 9$ & $17 \cdot 7,20 \cdot 0$ & & 1.02 & $0.95,1.09$ & \\
\hline-2 to $-1 \cdot 1$ & 308 & 3.0 & $2 \cdot 8,3 \cdot 2$ & & $17 \cdot 6$ & $17 \cdot 3,17 \cdot 8$ & & $20 \cdot 6$ & $20 \cdot 2,21 \cdot 0$ & & 1.04 & $1.01,1.06$ & \\
\hline-1 to 0 & 732 & 3.5 & $3.4,3.6$ & & $18 \cdot 2$ & $18 \cdot 1,18 \cdot 4$ & & $21 \cdot 6$ & $21 \cdot 4,21.9$ & & 1.04 & $1.03,1.06$ & \\
\hline $0 \cdot 1$ to 1 & 597 & $4 \cdot 0$ & $3 \cdot 9,4 \cdot 1$ & & $18 \cdot 9$ & $18 \cdot 7,19 \cdot 1$ & & $22 \cdot 9$ & $22 \cdot 6,23 \cdot 1$ & & 1.04 & $1.02,1.06$ & \\
\hline $1 \cdot 1$ to 2 & 204 & 4.6 & $4 \cdot 4,4 \cdot 8$ & & $19 \cdot 9$ & $19 \cdot 5,20 \cdot 2$ & & 24.5 & $24 \cdot 0,25 \cdot 0$ & & 1.04 & $1.01,1.07$ & \\
\hline$>2$ & 94 & $5 \cdot 7$ & $5 \cdot 4,6 \cdot 0$ & & $21 \cdot 2$ & $20 \cdot 7,21 \cdot 7$ & & $26 \cdot 8$ & $26 \cdot 1,27 \cdot 6$ & & 1.07 & $1 \cdot 02,1 \cdot 12$ & \\
\hline
\end{tabular}


Stunting has been suggested as a factor contributing to high rates of obesity in developing countries. The cross-sectional study of children from the four countries mentioned earlier (Popkin et al. 1996) showed significant associations between stunting and overweight at the individual level. Other crosssectional studies have also shown concurrent stunting and overweight or obesity in children (Koziel \& Jankowska, 2002; Mukuddem-Petersen \& Kruger, 2004; Jinabhai et al. 2005; Mamabolo et al. 2005). Findings from cross-sectional analyses may, however, be at least partly explained by a mathematical artefact in that, other things being equal, height will tend to be inversely related to a ratio of weight over height.

On the other hand, evidence from analyses of longitudinal studies is conflicting (Schroeder et al. 1999; Benefice et al. 2001; Walker et al. 2002; Martins et al. 2004; Cameron et al. 2005). A review in 2001 concluded that 'the evidence linking undernutrition to future risk of fatness is limited and contradictory' (Martorell et al. 2001).

The influence of undernutrition on body composition has also been investigated in a prospective study from Guatemala (Li et al. 2003). Linear growth retardation in early life (between 15 days and 2 years of age) was associated with a lower lean mass in young adulthood (between 21 and 27 years of age), but not with fat mass or percentage of body fat. In our study, stunting at age 2 and 4 years was not associated with lean mass index or FM:LM ${ }^{2 \cdot 3}$ ratio, but was associated with lower fat and body mass indices. Potential mechanisms for why early nutritional stunting may lead to an increased risk of obesity were studied in a selected group of children in Sao Paulo, Brazil (Hoffman et al. 2000; Martins et al. 2004; Grillol et al. 2005), but the findings were inconclusive.

The association between stunting and abdominal fatness was also analysed in the Guatemalan study, with contradictory results. In adults measured between 1988 and 1994, waist:hip ratio increased by 0.65 in men and 0.29 in women for each point decrease in height-for-age $Z$ score at 3 years of age (Schroeder et al. 1999), whereas waist:hip ratio measured in a follow-up studied carried out in 1998-99 was unrelated to growth in childhood (Li et al. 2003). In a longitudinal study carried out in a developed country (Laitinen et al. 2004), children who were small for gestational age showed a higher risk of abdominal adiposity at age 31 years. We did not investigate measures of fat distribution in the present study.

Our results showed no evidence that boys who were undernourished at age 2 or 4 years were more likely to be fatter when aged 18. On the contrary, such children had lower fat, lean and body mass indices, as well as a lower FM:LM ${ }^{2 \cdot 3}$ ratio. Our results suggest that undernutrition may partially protect against fatness at this age, and are consistent with those obtained when overweight and obesity - based on BMI and skinfolds - were assessed in the same cohort at the age of 15-16 years (Monteiro et al. 2003). These previous analyses did not, however, evaluate body composition outcomes.

The stronger association between outcomes measured at 18 years and anthropometric variables assessed at 4 years, when compared with those assessed at 2 years, may be interpreted as reflecting the 'horse-racing effect' (Peto, 1981). Horses or children - who are leading a race at a point closer to the finish line are more likely to win it than those leading at earlier parts of the track.
Confounding factors were selected to express socioeconomic and genetic determinants of child and adult anthropometry. Adjustment for these factors led to slight reductions in regression coefficients, suggesting that although these variables had positively confounded the association, they were far from explaining the findings of the present study.

In conclusion, the present results suggest that undernutrition in early life is not a risk factor for overweight or obesity. Our study differed from other longitudinal studies in the literature with respect to length of follow-up and number of subjects included in the analysis. In the present analyses, the associations between early nutrition and adolescent body composition were studied using fat, lean and body mass indices, and FM:LM ${ }^{2 \cdot 3}$ ratio; fat distribution was not, however, considered. Finally, only males were included in our study. Further analyses should be conducted including females and fat distribution measures.

\section{Acknowledgements}

This analysis was supported by the Wellcome Trust initiative Major Awards for Latin America on Health Consequences of Population Change. Earlier phases of the 1982 cohort study were funded by the International Development Research Center (Canada), the World Health Organization (Department of Child and Adolescent Health and Development, and Human Reproduction Programme), the Overseas Development Administration (UK), the UN Development Fund for Women, the National Program for Centers of Excellence (Brazil), the National Research Council (Brazil) and the Ministry of Health (Brazil).

\section{References}

Baird J, Fisher D, Lucas P, Kleijnen J, Roberts H \& Law C (2005) Being big or growing fast: systematic review of size and growth in infancy and later obesity. Br Med J 331, 929.

Barros FC, Victora CG \& Vaughan JP (1990) The Pelotas (Brazil) birth cohort study 1982-1987: strategies for following up 6,000 children in a developing country. Paediatr Perinat Epidemiol 4, 205-220.

Benefice E, Garnier D, Simondon KB \& Malina RM (2001) Relationship between stunting in infancy and growth and fat distribution during adolescence in Senegalese girls. Eur J Clin Nutr 55, 50-58.

Cameron N, Wright MM, Griffiths PL, Norris SA \& Pettifor JM (2005) Stunting at 2 years in relation to body composition at 9 years in African urban children. Obes Res 13, 131-136.

Grillol LP, Siqueira AF, Silva AC, Martins PA, Verreschi IT \& Sawaya AL (2005) Lower resting metabolic rate and higher velocity of weight gain in a prospective study of stunted vs nonstunted girls living in the shantytowns of Sao Paulo, Brazil. Eur J Clin Nutr 59, 835-842.

Hoffman DJ, Sawaya AL, Verreschi I, Tucker KL \& Roberts SB (2000) Why are nutritionally stunted children at increased risk of obesity? Studies of metabolic rate and fat oxidation in shantytown children from Sao Paulo, Brazil. Am J Clin Nutr 72, 702-707.

Jinabhai CC, Taylor M \& Sullivan KR (2005) Changing patterns of under- and over-nutrition in South African children-future risks of non-communicable diseases. Ann Trop Paediatr 25, 3-15.

Koziel S \& Jankowska EA (2002) Birthweight and stature, body mass index and fat distribution of 14-year-old Polish adolescents. $J$ Paediatr Child Health 38, 55-58. 
Laitinen J, Pietilainen K, Wadsworth M, Sovio U \& Jarvelin MR (2004) Predictors of abdominal obesity among 31-y-old men and women born in Northern Finland in 1966. Eur J Clin Nutr 58, 180-190.

Li H, Stein AD, Barnhart HX, Ramakrishnan U \& Martorell R (2003) Associations between prenatal and postnatal growth and adult body size and composition. Am J Clin Nutr 77, 1498-1505.

Maldonado G \& Greenland S (1993) Simulation study of confounderselection strategies. Am J Epidemiol 138, 923-936.

Mamabolo RL, Alberts M, Steyn NP, Delemarre-van de Waal HA \& Levitt NS (2005) Prevalence and determinants of stunting and overweight in 3-year-old black South African children residing in the Central Region of Limpopo Province, South Africa. Public Health Nutr 8, 501-508.

Martins PA, Hoffman DJ, Fernandes MT, Nascimento CR, Roberts SB, Sesso R \& Sawaya AL (2004) Stunted children gain less lean body mass and more fat mass than their non-stunted counterparts: a prospective study. Br J Nutr 92, 819-825.

Martorell R, Stein AD \& Schroeder DG (2001) Early nutrition and later adiposity. $J$ Nutr 131, 874S-880S.

Monteiro PO, Victora CG, Barros FC \& Monteiro LM (2003) Birth size, early childhood growth, and adolescent obesity in a Brazilian birth cohort. Int J Obes Relat Metab Disord 27, 1274-1282.

Mukuddem-Petersen J \& Kruger HS (2004) Association between stunting and overweight among 10-15-y-old children in the North West Province of South Africa: the THUSA BANA Study. Int J Obes Relat Metab Disord 28, 842-851.

National Center for Health Statistics (1977) NCHS Growth Curves for Children, Birth-18 Years. Washington, DC: NCHS.

Peto R (1981) The horse-racing effect. Lancet 2, 467-468.
Popkin BM, Richards MK \& Monteiro CA (1996) Stunting is associated with overweight in children of four nations that are undergoing the nutrition transition. J Nutr 126, 3009-3016.

Prentice AM (2006) The emerging epidemic of obesity in developing countries. Int J Epidemiol 35, 93-99.

Prentice AM \& Moore SE (2005) Early programming of adult diseases in resource poor countries. Arch Dis Child 90, 429-432.

Schroeder DG, Martorell R \& Flores R (1999) Infant and child growth and fatness and fat distribution in Guatemalan adults. Am J Epidemiol 149, 177-185.

Tanner JM (1990) Foetus into Man: Physical Growth from Conception to Maturity. Cambridge: Harvard University Press.

Victora CG \& Barros FC (2006) Cohort profile: the 1982 Pelotas (Brazil) Birth Cohort Study. Int J Epidemiol 35, 237-242.

Victora CG, Barros FC, Lima RC, Behague DP, Goncalves H, Horta BL, Gigante DP \& Vaughan JP (2003) The Pelotas Birth Cohort Study, Rio Grande do Sul, Brazil, 1982-2001. Cad Saude Publica 19, $1241-1256$.

Walker SP, Gaskin PS, Powell CA \& Bennett FI (2002) The effects of birth weight and postnatal linear growth retardation on body mass index, fatness and fat distribution in mid and late childhood. Public Health Nutr 5, 391-396.

Wells JCK, Gigante DP, Wright A, Hallal PC \& Victora CG (2003) Validation of leg-to-leg impedance for body composition assessment among Brazilian males aged 16-19 years. Int J Body Composition Res 1, 1-6.

Wells JC \& Victora CG (2005) Indices of whole-body and central adiposity for evaluating the metabolic load of obesity. Int $J$ Obes (Lond) 29, 483-489. 